\title{
Maternal well-being and its association to risk of developmental problems in children at school entry
}

Suzanne C Tough ${ }^{1,2^{*}}$, Jodi E Siever ${ }^{3}$, Karen Benzies ${ }^{4}$, Shirley Leew ${ }^{5}$, David W Johnston ${ }^{1,6}$

\begin{abstract}
Background: Children at highest risk of developmental problems benefit from early identification and intervention. Investigating factors affecting child development at the time of transition to school may reveal opportunities to tailor early intervention programs for the greatest effectiveness, social benefit and economic gain. The primary objective of this study was to identify child and maternal factors associated with children who screened at risk of developmental problems at school entry.

Methods: An existing cohort of 791 mothers who had been followed since early pregnancy was mailed a questionnaire when the children were aged four to six years. The questionnaire included a screening tool for developmental problems, an assessment of the child's social competence, health care utilization and referrals, and maternal factors, including physical health, mental health, social support, parenting morale and sense of competence, and parenting support/resources.

Results: Of the 491 mothers (62\%) who responded, 15\% had children who were screened at high risk of developmental problems. Based on a logistic regression model, independent predictors of screening at high risk for developmental problems at age 5 were male gender (OR: 2.3; $95 \% \mathrm{Cl}: 1.3,4.1$ ), maternal history of abuse at pregnancy (OR: 2.4; 95\% Cl: 1.3, 4.4), and poor parenting morale when the child was 3 years old (OR: 3.9; 95\% Cl: 2.1, 7.3). A child with all of these risk factors had a $35 \%$ predicted probability of screening at high risk of developmental problems, which was reduced to $13 \%$ if maternal factors were favourable.

Conclusions: Risk factors for developmental problems at school entry are related to maternal well being and history of abuse, which can be identified in the prenatal period or when children are preschool age.
\end{abstract}

\section{Background}

In the early years, unique opportunities exist to influence children's development trajectories and their families [1-4]. Birth to five years is a critical time in development when language, cognitive, emotional, social, behavioural and physical skills become the basis for the scaffolding of new skills throughout further experiences and education into adult life [4-6]. Childhood development has a demonstrable influence on long-term outcomes, affecting academic performance, health, coping skills and successes throughout the life course $[2,5,6]$. Evidence indicates that children at highest

\footnotetext{
* Correspondence: suzanne.tough@albertahealthservices.ca
${ }^{1}$ Department of Paediatrics, Faculty of Medicine, University of Calgary,

* Correspondence: suzanne.tough@albertahealthservices.ca
'Department of Paediatrics, Faculty of Medicine, University of Calgary, Calgary, Alberta, Canada
}

(c) 2010 Tough et al; licensee BioMed Central Ltd. This is an Open Access article distributed under the terms of the Creative Commons Attribution License (http://creativecommons.org/licenses/by/2.0), which permits unrestricted use, distribution, and reproduction in any medium, provided the original work is properly cited.

risk of developmental problems benefit from early identification and intervention [1-4]. Early interventions not only enhance the well-being of children and the resources of families but also benefit society by preventing and minimizing developmental problems and their costly consequences [1,3,7-11].

With an estimated 780 million young children around the world affected by an intellectual disability, the impact of developmental problems in society is widespread [4]. Understanding who is at risk in our community, and who would benefit from early intervention, allows for optimal allocation of limited resources. Investigating factors affecting child development at the time of school entry may reveal opportunities to tailor early intervention programs for the greatest effectiveness, social benefit and economic gain. 
It is well-known that sociodemographic characteristics of the family, such as low income and less maternal education, put children at higher risk for poor outcomes [10,12-14]. Recent evidence also suggests that, neighbourhood factors, such as neighbourhood income and cohesion, may also impact child development [15]. Males are at increased risk for developmental problems [14], and exposure to substances in utero impacts birth outcomes and child development $[16,17]$.

Maternal well-being and parenting have also been associated with child development. Harsh or inconsistent parenting approaches as well as maternal stress and anxiety have been associated with child behavioural outcomes $[9,18-21]$. A maternal history of abuse may also be associated with infant temperament and child behaviour [22,23]. Post-partum depression has been associated with poor cognitive and emotional development in infants, particularly among males, and these effects may persist into early childhood [14,19,24-28]. Predictable, appropriate responses to infants from adults are critical to optimal child development, and poor maternal mental health, in particular, can interfere with the creation of early infant-maternal social interactions that are stimulating and supportive [18-20]. Furthermore, parental models of attachment, family dysfunction, and family structure (e.g. lone parenting) have also been associated with parent-child interactions and behaviour problems in children $[9,12,13,29]$. Lack of maternal social support may also adversely impact child cognitive and behavioural development, most notably when mothers are dealing with depression or have a history of abuse $[22,30,31]$. The relationships among these maternal and family factors are complex as some factors may mediate the impact of others [22,29]. Furthermore, risk for delay and poor outcomes are cumulative such that children exposed to a greater number of risks have poorer outcomes than children exposed to less risk [13].

The study described in this paper follows up a cohort of mothers and children that have been studied on two previous occasions-during the perinatal period and when children were three years of age. Based in Calgary, an urban centre of over 1 million people in Alberta, Canada, the original Community Perinatal Care Study was a randomized controlled trial (RCT) of three types of prenatal care [32]. The results showed that additional prenatal support from nurses and home visitors could increase the use of community based resources and the access of pregnancy related information. The additional support, however, did not translate into changes in alcohol and tobacco use, post-partum depression or birth outcomes [32].

When the children in the Community Perinatal Care Study were followed up in a study at three years of age, the participants constituted a demographically low risk sample with regards to maternal education and income [14]. Of note, $73 \%$ of all Canadian families with kids under six years of age have a household income greater than or equal to $\$ 40,000$ [33]. The follow-up study at three years found that $11 \%$ of children screened at high risk of developmental problems [14]. Type of prenatal care received in the RCT did not have an impact on the child's risk for developmental problems at three years of age [14]. However, a male child who had a history of ear infections and was living in a low income environment with a mother with poor mental health (defined as a history of postpartum depression, abuse, and/or lack of contentment during pregnancy), had a predicted probability of $53 \%$ of having developmental problems at three years of age [14]. With all other variables held constant, this risk was reduced to $19 \%$ if the mother reported good mental health during the prenatal and early postpartum period, suggesting a meaningful potential benefit of interventions designed to address maternal mental health and well being [14].

The current study was conducted to answer questions about the health and development of a community based sample of children as they became of school age. The objectives of this study were to:

- identify the child and maternal factors associated with children who screened at risk of developmental and behavioural/emotional problems at five years of age,

- develop a model that predicts risk for developmental and behavioural/emotional problems at five years of age based on historical factors, and

- determine if the factors related to high risk for developmental problems at three years of age persisted as these children entered school.

For the purposes of this paper, developmental problems refer to a child's difficulties affecting development in any one, any combination, or all (i.e., global dysfunction) of the following domains: cognitive, social, language, motor, academics.

\section{Methods}

\section{Participants}

Participants in this study are part of a well-established cohort of women followed from early pregnancy to the time their children entered school. The original Community Perinatal Care (CPC) study began recruiting participants in 2000 through three family physician maternity clinics in the city of Calgary, inviting women at low medical risk to contribute to the study as they were seeking to begin prenatal care. In a randomized controlled trial, 1,737 women were assigned to three study groups, one receiving the current standard of 
prenatal care, a second receiving the same with the addition of consultation with a nurse trained in prenatal care, and the third receiving standard care, consultation with a trained nurse as well as home visits from a paraprofessional trained in non-medical prenatal care. Three computer-assisted telephone interviews followed over the course of the pregnancies in the first trimester, at 32-34 weeks gestation and eight weeks after delivery, and the women were also invited to participate in future research. Mothers who agreed to participate further formed the participant base for the first follow up study when their children were three years of age. With a focus on parenting and child development, the followup study at three years collected information from 791 women using telephone questionnaires and built on information from the cohort established during the original study. Detailed methods and full results from the CPC study and the first follow up study when children were three years of age are reported elsewhere [14,32]. Two years later, when the children were aged four to six years, the participants from the follow up study when children were three years of age formed the cohort for this second follow up study and received a mailed questionnaire. Mothers were excluded if they could not speak English and refused participation in the first follow up study.

\section{Questionnaire}

This questionnaire followed similar themes as were addressed in the follow up study when children were three years of age. In addition to demographic data, specific questions addressed the child's development, social competence, health care utilization, and referrals. Other questions addressed maternal physical health, emotional health, and social support as well as parenting, including morale, sense of competence, and supports and resources (see Additional file 1).

The questionnaire included six standardized measurement scales. One of these was the Parents' Evaluation of Development Status (PEDS), a 10 item parent-report screening measure to facilitate detection of risk for developmental and behaviour/emotional problems [34]. This was our primary outcome measure. Using the PEDS, parents report their concerns in 10 areas: global/ cognitive, expressive language, receptive language, fine motor, gross motor, behaviour, social-emotional, selfhelp, school, and other issues (typically medical or sensory) [35]. The PEDS screens children by level of risk for developmental disabilities and behavioural/emotional problems (i.e. assigns PEDS 'paths') with a sensitivity and specificity that ranges between $70 \%$ and $80 \%$ [34]. At $41 / 2$ to 6 years of age, concerns reported by parents in the global/cognitive, expressive language, receptive language, fine motor, gross motor, school, and other areas are predictive of developmental disabilities [35,36]. Scoring of the PEDS categorizes children into one of fives paths:

- Path A: high risk for developmental problems

- Path B: moderate risk for developmental problems

- Path C: low risk for developmental problems but elevated risk for behavioural/emotional problems

- Path D: parental communication difficulties

- Path E: low risk of developmental and behavioural/ emotional problems.

Also included were the Child Social Competence Scale for parents to assess pro-social behaviour, communication and self-control in the child, the SF- 8 to assess maternal physical and mental health, and the Medical Outcomes Study Social Support Scale to assess maternal social support [37-39]. To examine parenting further, the Parenting Sense of Competence Scale and the Parenting Morale Index were included as well $[40,41]$. The Parenting Morale Index measures "parenting zeal, enthusiasm, and capability to endure hardship" by measuring the frequency of ten emotional states of parents, and the internal consistency of this relatively new scale is strong (Cronbach's alpha $=0.84$ ) [41]. Table 1 contains detailed information on the standardized measurement scales that were part of the questionnaire. The entire questionnaire was pilot tested with 10 mothers for length, flow, and comprehension and was revised as per comments and consultations.

Questionnaires were mailed to the 791 respondents from the first follow up study with a cover sheet detailing their voluntary participation, confidentiality and the links that would be made to previously collected data. The questionnaire took approximately 15-20 minutes to complete. It was requested that the questionnaire be mailed back within two weeks, after which time telephone calls were made to offer an alternative response mode. Women were considered unreachable if they could not be contacted by telephone due to a change in phone number and alternate contacts could not be reached. Data collection began in August 2007 and was completed by January 2008. Questionnaires were scanned and verified in Teleform, an electronic data capture and management system [42]. Ethics approval was granted to the study from the Conjoint Health Research Ethics Board at the University of Calgary.

\section{Analysis}

The data collected through the questionnaires were linked to data from the original CPC study as well as to the first follow up study using unique study identification numbers. This resulted in data for mothers at five time points from the first trimester to 5 years post 


\begin{tabular}{|c|c|}
\hline Scale & Description \\
\hline $\begin{array}{l}\text { Parents' Evaluation of Development } \\
\text { Status (PEDS) }\end{array}$ & $\begin{array}{l}\text { The PEDS is a parent-reported screening measure to facilitate detection of developmental and behavioural/ } \\
\text { emotional problems [34]. The scale contains } 10 \text { items: global/cognitive, expressive language, receptive } \\
\text { language, fine motor, gross motor, behaviour, social-emotional, self-help, school, and other issues (typically } \\
\text { medical or sensory) [35]. Scoring of the PEDS categorizes children into one of five paths, depending on their } \\
\text { level of risk for developmental and behavioural/emotional problems. }\end{array}$ \\
\hline Child Social Competence Scale & $\begin{array}{l}\text { Using a 5-point Likert scale, the Social Competence Scale - Parent Version assesses a child's prosocial } \\
\text { behaviours, communication skills, and self control. The scale has two subscales: prosocial/communication skills } \\
\text { and emotional regulation skills. The scale has } 12 \text { items that each refer to a behaviour that a child may exhibit } \\
\text { in a social setting. The parent reports how well each statement describes the child. Examples of statements } \\
\text { include: "Your child can give suggestions and opinions without being bossy" and "Your child can calm down } \\
\text { when excited or 'all wound up"' [37]. }\end{array}$ \\
\hline SF-8 & $\begin{array}{l}\text { The SF-8 Health Survey is a widely used generic multipurpose short-form (SF) survey of health status with sub- } \\
\text { scales for mental and physical health. The scale has eight items to measure eight domains of health: physical } \\
\text { functioning, role-physical, bodily pain, general health, vitality, social functioning, role-emotional, and mental } \\
\text { health [38]. }\end{array}$ \\
\hline $\begin{array}{l}\text { Medical Outcomes Study Social } \\
\text { Support Scale }\end{array}$ & $\begin{array}{l}\text { Using a 5-point Likert scale, the Medical Outcomes Study Social Support Scale measures functional social } \\
\text { support according to four subscales and also provides an overall measure of support. The scale has } 19 \text { items, } \\
\text { and respondents indicate how often each kind of support was available to them if they need it. The four } \\
\text { subscales are: emotional/informational ("the expression of positive affect, empathetic understanding, the } \\
\text { encouragement of expression of feelings" and "the offering of advice, information, guidance, or feedback"), } \\
\text { tangible ("the provision of material aid or behavioral assistance"), affection ("expressions of love and affection"), } \\
\text { and positive social interaction ("other people to do fun things with you") [39]. }\end{array}$ \\
\hline $\begin{array}{l}\text { Parenting Sense of Competence } \\
\text { Scale }\end{array}$ & $\begin{array}{l}\text { Using a 6-point Likert scale, the Parenting Sense of Competence Scale assesses the degree to which a parent } \\
\text { feels competent and confident in handling a child's problems and the degree of satisfaction they associate } \\
\text { with parenting. The scale contains } 16 \text { items. Examples of items include: "Being a parent is manageable, and } \\
\text { any problems are easily solved" and "Sometimes I feel like I'm not getting anything done" [40]. }\end{array}$ \\
\hline Parenting Morale Index (PMI) & $\begin{array}{l}\text { Using a 5-point Likert scale, the PMI measures how frequently parents experience ten emotional states } \\
\text { (optimistic, worried, contented, frustrated, satisfied, happy, stressed, lonely, exhausted, and guilty). The scale } \\
\text { contains } 10 \text { items [41]. }\end{array}$ \\
\hline
\end{tabular}

partum. Data were analyzed using the statistical package Stata/SE Version 10.0 [43]. The data analysis included descriptive methods for categorical data as well as bivariate and multivariate methods. Based on the PEDS scoring, children were categorized into one of the five PEDS paths (Path A, B, C, D, or E), which indicated the level of risk for developmental and behavioural/emotional problems as noted above. The variables based on the Child Social Competence Scale, SF-8, Medical Outcomes Study Social Support Scale, Parenting Sense of Competence Scale, and Parenting Morale Index were dichotomized at the value closest to the $25^{\text {th }}$ percentile. Scores equal to or below this cutoff were categorized as high risk while scores above the cutoff were categorized as low risk. During the prenatal period, women had been asked about abuse in the following way: "Abuse can take many forms: physical, emotional (including psychological or verbal), sexual, financial (e.g. withholding or controlling money) or neglect. We ask all participants in this study about abuse in their lives. Have you ever been physically abused, emotionally abused, sexually abused, financially abused, or neglected?" Women who indicated they had been abused in any form were considered to have a history of abuse.

Bivariate analysis, using Fisher's exact test, was undertaken to compare PEDS paths on child and maternal characteristics. Statistical significance was set at $\mathrm{p}<0.05$. A multinomial logistic regression model was constructed to explore the relationship between risk of developmental problems and historical factors associated with this risk, yielding odds ratios and 95\% confidence intervals. Variables in the bivariate analysis were considered eligible for inclusion in the regression modeling if they were significant at $\mathrm{p} \leq 0.10$, or if prior evidence or theoretical considerations supported their inclusion. Characteristics of the child were entered into the regression model first (e.g. gender, ear infections prior to age two), then maternal measures (e.g. parenting morale, social support, physical health, mental health), and lastly socio-demographic measures. In addition, variables were entered into the model from past to present (e.g. history of abuse reported at pregnancy was entered before parenting morale measured at 3 years post partum). When measurement scales had subscales, the overall index was used in the regression model. Selected predicted probabilities for screening in each PEDS path were also calculated. Although the current study was a follow-up of a cohort over a period of over 5 years, data on child development were only collected at two points, thus limiting our ability to conduct a longitudinal analysis of the child development data. 


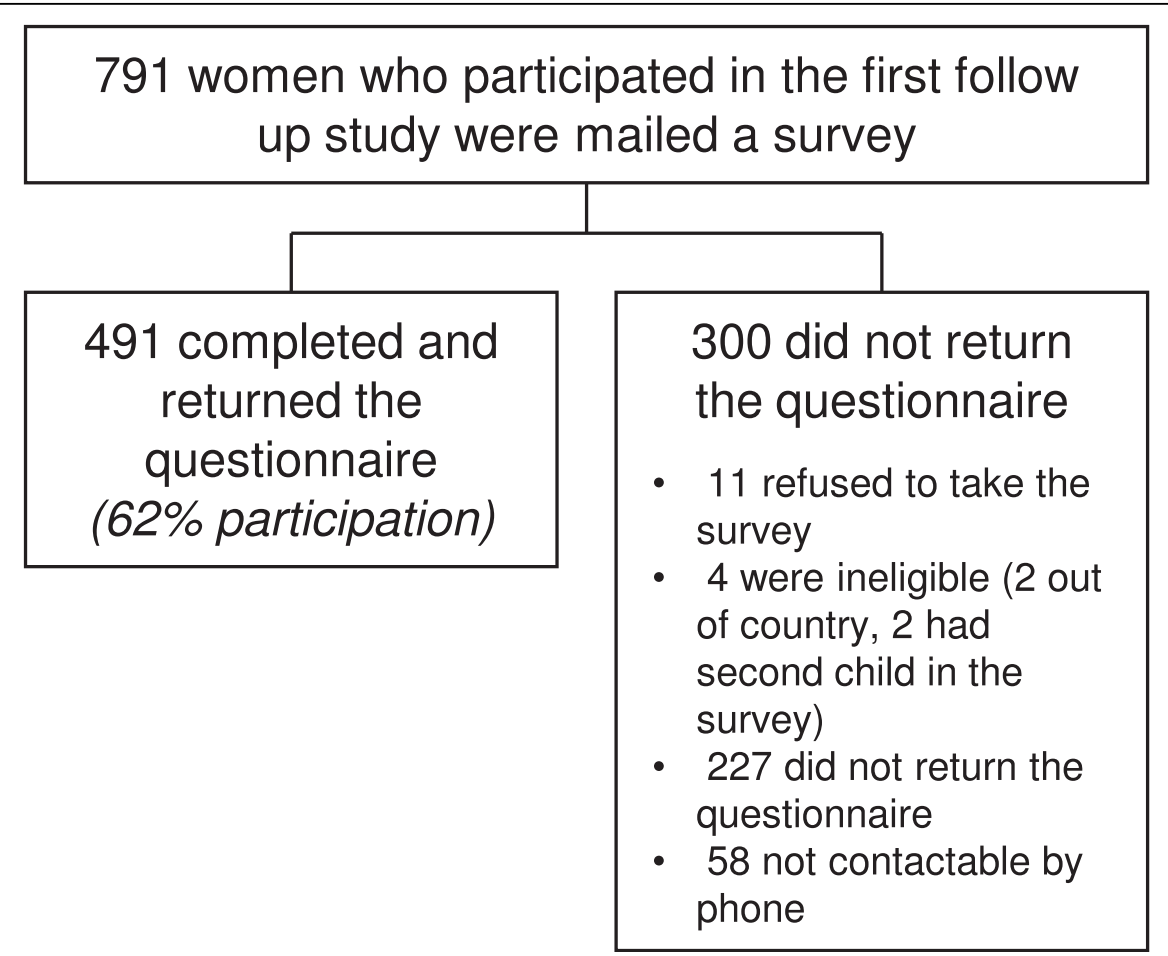

Figure 1 Study flowchart mapping eligibility, recruitment, and completion of mothers who participated in the study

\section{Results}

Participation and characteristics

Of the 791 respondents in the three year follow up study, 491 returned questionnaires when their children were at school entry, resulting in a $62 \%$ response rate (Figure 1 ). The majority of mothers who participated were married or with a partner, educated at a post-secondary level and had a household income over $\$ 40,000$ per year (Table 2 ). Almost half reported being a homemaker. The average age of the children was five years, and about half were male. The majority of previous referrals had been to speech and language pathologists. Thirty-two percent of women reported a history of abuse when asked during pregnancy. Of the total sample, 61 women reported physical abuse (12.4\%), 110 emotional abuse (22.4\%), 65 sexual abuse (13.2\%), 20 financial abuse (4.1\%), and 16 neglect (3.3\%). Mothers who were lost to follow up and did not participate in this study were more likely to have reported the following in the previous study: smoking, not having attended parenting classes or been pregnant again, poor physical health ratings, incomes less than $\$ 40,000$ per year, less than a high school education, being single or divorced and/or being less than 25 years of age (all $\mathrm{p}<$ 0.05 , data not tabled). There was no association between the type of prenatal care women had received during the RCT and the risk of developmental problems in their children at school age.

\section{Children's development and behaviour}

Analysis of the PEDS revealed that 15\% ( $n=72)$ of the children screened at the highest risk of developmental problems (Path A). Of these 72, 53\% $(n=38)$ had at least one referral for further assessment or intervention since birth with $33 \%(n=24)$ referred within the last year. Thirty-one percent $(n=153)$ of the children screened at moderate risk of developmental problems (Path B). Nineteen percent $(n=93)$ of the children screened in Path $C$ which suggests low risk for developmental problems but elevated risk for behavioural/emotional problems. The remaining 35\% $(\mathrm{n}=$ 172) of children were screened to Path E which suggests a low risk of either developmental or behavioural/emotional problems. None of the respondents were screened in Path D for parental communication difficulties. Of concerns reported by parents that are predictive of developmental problems, the most commonly reported was expressive language. Of concerns that are not predictive of developmental problems, behavioural and social-emotional concerns were reported most often by the mothers.

\section{Factors associated with risk of developmental problems}

An increased risk for developmental problems was associated with lower social competence scores for children $(\mathrm{p}<0.001)$ (Table 3). Of the children at high risk for developmental problems or elevated risk for behavioural/emotional problems (Path $\mathrm{A}$ or $\mathrm{C}$ ), more than 
Table 2 Characteristics of mothers and children who participated in the follow up study

\begin{tabular}{|c|c|c|}
\hline Characteristic & $\begin{array}{l}N= \\
491\end{array}$ & \\
\hline Mothers & Mean & sd \\
\hline \multirow[t]{2}{*}{ Age } & 36.3 & 4.4 \\
\hline & $\mathrm{n}$ & $\%$ \\
\hline \multicolumn{3}{|l|}{ Marital Status } \\
\hline Married/Commonlaw & 473 & 95.0 \\
\hline Divorced/Separated & 17 & 3.4 \\
\hline Single/Widowed & 8 & 1.6 \\
\hline \multicolumn{3}{|l|}{ Main Activity } \\
\hline Working at a job or business (full/part-time) & 208 & 42.6 \\
\hline Homemaker & 226 & 46.2 \\
\hline Looking for work & 2 & 0.4 \\
\hline Paid maternity leave & 28 & 5.7 \\
\hline Student & 5 & 1.0 \\
\hline Other & 20 & 4.1 \\
\hline \multicolumn{3}{|l|}{ Household Income } \\
\hline$\leq \$ 39,999$ & 24 & 4.9 \\
\hline$\$ 40,000-\$ 79,999$ & 124 & 25.5 \\
\hline$\$ 80,000-\$ 119,999$ & 154 & 31.6 \\
\hline$\geq \$ 120,000$ & 149 & 30.6 \\
\hline Prefer not to answer & 36 & 7.4 \\
\hline \multicolumn{3}{|l|}{ Education } \\
\hline Less than high school & 0 & 0.0 \\
\hline High school & 80 & 16.4 \\
\hline College/trade & 158 & 32.3 \\
\hline University & 197 & 40.3 \\
\hline Post graduate studies & 54 & 11.0 \\
\hline Moved once or more in the past year & 93 & 19.2 \\
\hline Children & Mean & sd \\
\hline \multirow[t]{2}{*}{ Age } & 5.0 & 0.6 \\
\hline & $n$ & $\%$ \\
\hline Male & 240 & 48.9 \\
\hline Child has had routine health exam in the past year & 394 & 80.7 \\
\hline $\begin{array}{l}\text { Child has had his/her vision or eyes checked in the past } \\
\text { year }\end{array}$ & 261 & 53.8 \\
\hline Child has had his/her hearing tested in the past year & 58 & 12.0 \\
\hline Child has seen a dentist in the past year & 436 & 89.0 \\
\hline \multicolumn{3}{|l|}{ In the past year, child has been referred to: } \\
\hline $\begin{array}{l}\text { Early intervention program } \\
\text { Speech and language pathologist }\end{array}$ & $\begin{array}{c}6 \\
57\end{array}$ & $\begin{array}{r}1.2 \\
11.6\end{array}$ \\
\hline Child developmental paediatrician & 14 & 2.9 \\
\hline Psychologist & 11 & 2.2 \\
\hline Physiotherapist & 5 & 1.0 \\
\hline Dietician & 5 & 1.0 \\
\hline
\end{tabular}

Note: Denominator varies due to missing data on some survey items.
$40 \%$ also scored in the lowest quartile of overall social competence. Male children were also significantly more likely to screen at risk of developmental problems (Table 3).

The children of mothers who reported poor mental health and low social support were significantly more likely to screen at high risk for developmental problems (Path A) (Table 3). Poor mental health was reported by $37 \%$ of mothers with children in Path A but by only $17 \%$ of mothers with children in Path $E(p=0.004)$ (Table 3). Of the mothers with children in Path A, 46\% scored in the lowest quartile for current social support while just $19 \%$ of mothers with children in Path $\mathrm{E}$ scored in the same quartile ( $\mathrm{p}<0.001)$ (Table 3). Parenting sense of competence and morale were also associated with a high risk for developmental problems (Table 3). Forty percent of mothers with children in Path A scored in the lowest quartile of parenting efficacy and satisfaction with parenting ( $\mathrm{p}<0.035)$ compared to $20 \%$ of mothers with children in Path E, and $32 \%$ of mothers in Path A compared to $7 \%$ of mothers in Path E scored in the lowest quartile for parenting morale $(\mathrm{p}<0.001)$ (Table 3).

Children who were screened at risk for developmental problems were significantly more likely to have mothers who, during pregnancy, had reported a history of abuse and poor social support $(\mathrm{p}<0.05)$ (Table 3). They were also more likely to have mothers who reported poor physical health and poor parenting morale when their child was three years $(\mathrm{p}<0.05)$ (Table 3$)$. In the bivariate analysis, no significant differences were found in income, education or marital status between Paths.

\section{Key predictors of screening for high risk of developmental problems}

Multinomial logistic regression analysis revealed that the most significant predictors of having a child who was screened at high risk (Path A) compared to low risk of developmental problems included a child who was male, a mother who had reported a history of abuse while pregnant and poor parenting morale when her child was three years old (Table 4). Based on the logistic regression model, a boy, whose mother had a history of abuse and poor parenting morale, had a $35 \%$ predicted probability of screening at high risk of developmental problems (Path A) (Table 5). However, a boy, whose mother had no history of abuse and a history of good parenting morale, had a $13 \%$ predicted probability of screening at high risk of developmental problems. 
Table 3 Maternal and child characteristics, by PEDS path of child

\begin{tabular}{|c|c|c|c|c|c|c|}
\hline Scale & $\begin{array}{c}\text { Path A } \\
\text { (high risk for } \\
\text { developmental } \\
\text { problems) } \\
\mathrm{N}=72 \\
\mathrm{n}(\%)\end{array}$ & $\begin{array}{c}\text { Path B } \\
\text { (moderate risk for } \\
\text { developmental problems) } \\
\mathrm{N}=153 \\
\mathrm{n}(\%)\end{array}$ & $\begin{array}{c}\text { Path C } \\
\text { (elevated risk for } \\
\text { behavioural/emotional } \\
\text { problems) } \\
\mathrm{N}=93 \\
\mathrm{n}(\%)\end{array}$ & $\begin{array}{c}\text { Path } \mathrm{E} \\
\text { (low risk for } \\
\text { problems) } \\
\mathrm{N}=172 \\
\mathrm{n}(\%)\end{array}$ & $\begin{array}{c}\text { Total } \\
\mathrm{N}= \\
490 \\
\mathrm{n} \\
(\%)\end{array}$ & $\begin{array}{c}\mathrm{p}- \\
\text { value }\end{array}$ \\
\hline \multicolumn{7}{|l|}{ Child Factors } \\
\hline Male & $45(63)$ & $82(54)$ & $43(46)$ & $70(41)$ & $\begin{array}{l}240 \\
(49)\end{array}$ & 0.009 \\
\hline Ear infections prior to age 2 & $29(41)$ & $52(35)$ & $37(40)$ & $56(33)$ & $\begin{array}{l}174 \\
(36)\end{array}$ & 0.503 \\
\hline $\begin{array}{l}\text { Poor overall social } \\
\text { competence* }\end{array}$ & $32(45)$ & $40(26)$ & $38(41)$ & $30(17)$ & $\begin{array}{l}140 \\
(29) \\
\end{array}$ & $<0.001$ \\
\hline $\begin{array}{l}\text { Poor prosocial/ } \\
\text { communication skills* }\end{array}$ & $30(42)$ & $40(26)$ & $32(34)$ & $21(12)$ & $\begin{array}{l}123 \\
(25) \\
\end{array}$ & $<0.001$ \\
\hline $\begin{array}{l}\text { Poor emotional } \\
\text { regulation skills* }\end{array}$ & $35(49)$ & $44(29)$ & $41(44)$ & $35(20)$ & $\begin{array}{l}155 \\
(32) \\
\end{array}$ & $<0.001$ \\
\hline \multicolumn{7}{|l|}{ Current Maternal Factors } \\
\hline \multicolumn{7}{|l|}{ SF-8 } \\
\hline Poor physical health* & $25(36)$ & $39(26)$ & $22(24)$ & $35(21)$ & $\begin{array}{l}121 \\
(25) \\
\end{array}$ & 0.114 \\
\hline Poor mental health* & $26(37)$ & $45(30)$ & $21(23)$ & $29(17)$ & $\begin{array}{l}121 \\
(25) \\
\end{array}$ & 0.004 \\
\hline \multicolumn{7}{|l|}{ Social Support } \\
\hline $\begin{array}{l}\text { Poor emotional/ } \\
\text { informational support* }\end{array}$ & $27(40)$ & $34(23)$ & $29(32)$ & $30(18)$ & $\begin{array}{l}120 \\
(25) \\
\end{array}$ & 0.003 \\
\hline Poor tangible support* & $28(41)$ & $45(30)$ & $29(31)$ & $44(26)$ & $\begin{array}{l}146 \\
(30) \\
\end{array}$ & 0.139 \\
\hline $\begin{array}{l}\text { Poor positive } \\
\text { interaction* }\end{array}$ & $32(47)$ & $45(30)$ & $28(30)$ & $38(22)$ & $\begin{array}{l}143 \\
(30) \\
\end{array}$ & 0.003 \\
\hline Poor affection* & $30(43)$ & $34(22)$ & $26(28)$ & $37(22)$ & $\begin{array}{l}127 \\
(26)\end{array}$ & 0.006 \\
\hline $\begin{array}{l}\text { Poor overall support } \\
\text { index* }\end{array}$ & $31(46)$ & $35(24)$ & $27(30)$ & $32(19)$ & $\begin{array}{l}125 \\
(27)\end{array}$ & $<0.001$ \\
\hline \multicolumn{7}{|l|}{$\begin{array}{l}\text { Parenting Sense of } \\
\text { Competence }\end{array}$} \\
\hline Low efficacy* & $27(40)$ & $37(25)$ & $27(29)$ & $35(21)$ & $\begin{array}{l}126 \\
(27)\end{array}$ & 0.033 \\
\hline Low satisfaction* & $28(41)$ & $36(24)$ & $29(32)$ & $31(18)$ & $\begin{array}{l}124 \\
(26)\end{array}$ & 0.002 \\
\hline Poor parenting morale* & $31(46)$ & $43(28)$ & $30(33)$ & $33(20)$ & $\begin{array}{l}137 \\
(28)\end{array}$ & 0.001 \\
\hline \multicolumn{7}{|l|}{ Historical Maternal Factors } \\
\hline $\begin{array}{l}\text { Poor parenting morale at } 3 \\
\text { years post partum }\end{array}$ & $31(43)$ & $40(26)$ & $25(27)$ & $28(16)$ & $\begin{array}{l}124 \\
(25) \\
\end{array}$ & $<0.001$ \\
\hline $\begin{array}{l}\text { Poor physical health at } 3 \\
\text { years }\end{array}$ & $24(33)$ & $34(22)$ & $21(23)$ & $27(16)$ & $\begin{array}{l}106 \\
(22)\end{array}$ & 0.024 \\
\hline $\begin{array}{l}\text { Poor social support at } 3 \\
\text { years post partum }\end{array}$ & $12(17)$ & $15(10)$ & $10(11)$ & $15(9)$ & $\begin{array}{l}52 \\
(11)\end{array}$ & 0.324 \\
\hline $\begin{array}{l}\text { Depression for } 2 \text { or more } \\
\text { weeks post partum }\end{array}$ & $32(44)$ & $52(34)$ & $32(34)$ & $52(30)$ & $\begin{array}{l}168 \\
(34) \\
\end{array}$ & 0.212 \\
\hline $\begin{array}{l}\text { Poor social support during } \\
\text { pregnancy }\end{array}$ & $17(24)$ & $32(21)$ & $23(25)$ & $22(13)$ & $\begin{array}{c}94 \\
(19) \\
\end{array}$ & 0.045 \\
\hline $\begin{array}{l}\text { Low score on positive } \\
\text { feelings during pregnancy }\end{array}$ & $21(29)$ & $46(30)$ & $33(35)$ & $44(25)$ & $\begin{array}{l}144 \\
(29)\end{array}$ & 0.406 \\
\hline $\begin{array}{l}\text { History of abuse, at } \\
\text { pregnancy }\end{array}$ & $30(42)$ & $56(37)$ & $33(35)$ & $38(22)$ & $\begin{array}{l}157 \\
(32)\end{array}$ & 0.004 \\
\hline
\end{tabular}


Table 3: Maternal and child characteristics, by PEDS path of child (Continued)

\begin{tabular}{|c|c|c|c|c|c|c|}
\hline \multicolumn{7}{|l|}{$\begin{array}{l}\text { Maternal Socio- } \\
\text { Demographic Factors }\end{array}$} \\
\hline Income $<\$ 80,000$ & $29(40)$ & $48(31)$ & $26(28)$ & $45(26)$ & $\begin{array}{l}158 \\
(30) \\
\end{array}$ & 0.169 \\
\hline $\begin{array}{l}\text { No post-secondary } \\
\text { education }\end{array}$ & $13(18)$ & $24(16)$ & $17(18)$ & $26(15)$ & $\begin{array}{c}80 \\
(16)\end{array}$ & 0.881 \\
\hline $\begin{array}{l}\text { No marriage or common- } \\
\text { law partner }\end{array}$ & $8(11)$ & $5(3)$ & $5(5)$ & $7(4)$ & $\begin{array}{l}25 \\
(5)\end{array}$ & 0.102 \\
\hline
\end{tabular}

*Children or mothers scoring in the lowest quartile of these measures.

Note: Denominator varies due to missing data on some survey items. The denominator is not 491 in this table because one mother completed only half of the PEDS survey as her questionnaire was missing a page.

Similarly, the predicted probability of screening at high risk for developmental problems for a girl, whose mother had a history of abuse and poor parenting morale, was $24 \%$. A girl, whose mother had no history of abuse and a history of good parenting morale, had a 7\% probability of screening at high risk for developmental problems (Table 5).

\section{Discussion}

This study indicates a direct relationship between the well being of mothers and the development of their children at school entry [14]. Maternal history of abuse reported during the prenatal period and past parenting morale were independent predictors of high risk for childhood developmental problems at school entry. Mothers of children at high risk for developmental problems were also more likely to have lower scores in measures of current mental health and parenting morale, as well as current and past social support.

This study and the previous follow-up study at three years suggests that the direct relationship between the well-being of mothers and the development of their children begins in the early years and persists through to school entry [14]. These findings suggests that children may not 'rebound' from early threats to development that occur before age 3 simply through maturity, independence or through increased interactions outside the home. This work highlights the critical importance of maternal well being and parenting morale in child development, and emphasizes that these can be unrelated to economic security and maternal education.

In particular, children of mothers who reported a history of abuse while pregnant were more than twice as likely to be at risk for developmental problems at three years and at five years [14]. These findings suggest that identifying women with a history of abuse may be one way to identify women whose children are at higher risk of developmental problems. Based on the findings from this study, identification of these women could take place as early as the prenatal period. However, further studies are required to better understand how we can identify and intervene with women in the prenatal period to remediate barriers to optimal parenting and child development outcomes [44-46]. Nevertheless, the finding that about a third of this population reported a history of abuse speaks to the potentially pervasive experience of abuse across all socio-economic domains and highlights opportunities for improved access to services and supports to address past abuse.

It is important to note that maternal history of abuse, poor parenting morale, and poor maternal social support were all associated with highest risk of developmental problems (Path A) at school entry in the bivariate analysis, but maternal history of abuse and poor parenting morale were more predictive in the logistic regression model of a child screening in Path A when accounting for other factors. This may be due to the relationship among these variables. Past research has demonstrated that women in abusive situations often have poor social support, resulting from the social systems that create an environment conducive to abuse or the social isolation imposed on women by those who abuse them $[46,47]$. Women who report a history of abuse, regardless of current socio-demographic circumstances, may be less willing or able to engage in supportive social relationships due to their view of self or others [46].

Children at high risk for developmental problems were more likely to have mothers who had low parenting morale when their children were three years old. It may be that mothers with low parenting morale are particularly sensitive to difficulties that may be emerging in their children, or that a child's emerging developmental difficulties and a mother's parenting morale influence each other in a reciprocal fashion. Considering this, support to parents that address sense of competence and morale may positively impact parental well being and child development.

In this study, $15 \%$ of children screened at high risk of developmental problems, similar to the proportion found when this cohort of children was three years of age. Although most children had had routine medical 
Table 4 Key predictors for scoring at risk of developmental problems on the PEDS, $\mathbf{N}=\mathbf{4 9 0}$

\begin{tabular}{|c|c|c|c|}
\hline Variable & $\begin{array}{l}\text { Unadjusted Odds Ratio (95\% C. } \\
\text { I.) }\end{array}$ & $\begin{array}{c}\text { Adjusted Odds } \\
\text { Ratio } \\
\text { (95\% C.I.) } \\
\end{array}$ & $\begin{array}{c}\mathrm{p}- \\
\text { value }\end{array}$ \\
\hline \multicolumn{4}{|l|}{ Path A (high risk for developmental problems) } \\
\hline \multicolumn{4}{|l|}{ Child Characteristics } \\
\hline Male & $2.4(1.4,4.3)$ & $2.3(1.3,4.1)$ & 0.005 \\
\hline \multicolumn{4}{|l|}{ Maternal Characteristics } \\
\hline Poor parenting morale, at 3 years post partum & $3.9(2.1,7.2)$ & $3.9(2.1,7.3)$ & $<0.001$ \\
\hline History of abuse, at pregnancy & $2.5(1.4,4.6)$ & $2.4(1.3,4.4)$ & 0.006 \\
\hline \multicolumn{4}{|l|}{ Path B (moderate risk for developmental problems) } \\
\hline \multicolumn{4}{|l|}{ Child Characteristics } \\
\hline Male & $1.7(1.1,2.6)$ & $1.6(1.0,2.5)$ & 0.033 \\
\hline \multicolumn{4}{|l|}{ Maternal Characteristics } \\
\hline Poor parenting morale, at 3 years post partum & $1.8(1.1,3.1)$ & $1.8(1.0,3.1)$ & 0.034 \\
\hline History of abuse, at pregnancy & $2.0(1.2,3.3)$ & $2.0(1.2,3.2)$ & 0.007 \\
\hline \multicolumn{4}{|c|}{$\begin{array}{l}\text { Path C (elevated risk for behavioral and/or behavioural/emotional } \\
\text { problems) }\end{array}$} \\
\hline \multicolumn{4}{|l|}{ Child Characteristics } \\
\hline Male & $1.3(0.8,2.1)$ & $1.2(0.7,2.0)$ & 0.464 \\
\hline \multicolumn{4}{|l|}{ Maternal Characteristics } \\
\hline Poor parenting morale, at 3 years post partum & $1.9(1.0,3.5)$ & $1.9(1.0,3.5)$ & 0.044 \\
\hline History of abuse, at pregnancy & $1.9(1.1,3.4)$ & $1.9(1.1,3.4)$ & 0.023 \\
\hline
\end{tabular}

checkups, only about half of those who screened at high risk of developmental problems based on parents' concerns had been previously referred for assessments or interventions. The common practice among physicians for developmental surveillance is subjective clinical observation which identifies only $30-50 \%$ of children with developmental delay $[48,49]$. Physicians' developmental screening often focuses on sensory deficits, with less attention to developmental and behavioural/emotional problems. Reliable screening approaches would greatly improve the rate of identification [50]. Finding solutions for providing accessible, valid and reliable identification of developmental and behavioural/emotional problems with appropriate interventions for children and families at risk would benefit all of society.

Although the women most likely to participate in the study had high levels of education and household incomes, the sample aligns with the income level of three-quarters of all Canadian families with kids under six years of age and the educational attainment of three-

Table 5 Predicted probability for scoring at risk of developmental problems on the PEDS, from the multinomial logistic regression model

\begin{tabular}{|c|c|c|c|c|c|c|}
\hline \multirow{2}{*}{$\begin{array}{c}\text { Child } \\
\text { Characteristics } \\
\text { Gender }\end{array}$} & \multicolumn{2}{|c|}{ Maternal Characteristics } & \multicolumn{4}{|c|}{ Predicted Probability of Screening in Each PEDS Path } \\
\hline & $\begin{array}{l}\text { History of } \\
\text { Abuse, at } \\
\text { pregnancy }\end{array}$ & $\begin{array}{l}\text { Parenting Morale, at } \\
3 \text { Years Post Partum }\end{array}$ & $\begin{array}{c}\text { Path A } \\
\text { (high risk for } \\
\text { developmental } \\
\text { problems) }\end{array}$ & $\begin{array}{c}\text { Path B } \\
\text { (moderate risk for } \\
\text { developmental } \\
\text { problems) }\end{array}$ & $\begin{array}{c}\text { Path C } \\
\text { (elevated risk for } \\
\text { behavioural/emotional } \\
\text { problems) }\end{array}$ & $\begin{array}{c}\text { Path E } \\
\text { (low risk } \\
\text { for } \\
\text { problems) }\end{array}$ \\
\hline Boy & Yes & Poor & 0.35 & 0.35 & 0.18 & 0.12 \\
\hline Boy & No & Poor & 0.27 & 0.33 & 0.18 & 0.22 \\
\hline Girl & Yes & Poor & 0.24 & 0.34 & 0.24 & 0.18 \\
\hline Boy & Yes & Good & 0.18 & 0.39 & 0.20 & 0.23 \\
\hline Girl & No & Poor & 0.17 & 0.29 & 0.22 & 0.32 \\
\hline Boy & No & Good & 0.13 & 0.32 & 0.17 & 0.39 \\
\hline Girl & Yes & Good & 0.11 & 0.33 & 0.23 & 0.33 \\
\hline Girl & No & Good & 0.07 & 0.25 & 0.18 & 0.49 \\
\hline
\end{tabular}


quarters of Canadian women giving birth [33,51]. The results then are generalizable to the majority of Canadian families with children under six. Furthermore, 15\% of children screened at highest risk of developmental problems, as would be anticipated in a population based setting.

Despite our attempts to follow-up women in the study, mothers who were younger, had lower education and income, had poor physical health, were single or divorced, and smoked were more likely to be unreachable or not respond to follow-up attempts. Thus, these findings cannot be generalized to this more vulnerable population. In other research, these factors have been associated with increased risk for poor infant outcomes and child developmental problems, and consequently, the results potentially underestimate the proportion of the total population of preschool children at risk of problems [10,12-14,19,52-54].

It is important to consider that the factors associated with women who were not retained in the cohort (young maternal age, low education and income, poor physical health, being single, and smoking) are similar to the characteristics of women who are difficult to retain in studies and in longitudinal research [55]. These factors may signal complex health, lifestyle, and social issues that these women face which make it difficult to retain them [56]. Also, the original study was a community based study that was not initially designed to be a longitudinal follow-up study. Thus, traditional strategies to retain women (e.g. incentives, changes of address cards, and routine follow-up) were not implemented immediately after the first study. However, retention strategies were implemented between the follow-up study at 3 years and at 5 years (e.g. routine contact, asking women to inform us of an upcoming change in contact information). In all three studies, the participation rates were over $60 \%$, and the women not retained in the cohort appear to be similar among all three studies.

Because this sample included few women who had a household income less than $\$ 40,000$ and none who had less than a high school education, the current study did not find differences in developmental risk by education or income level. Nevertheless, this study raises the consideration that although children may not be at risk for developmental problems due to maternal education or family income, other factors may place children at risk for developmental problems. It is noteworthy that the women in this study would be commonly defined as a "low risk" population considering their demographic information. However, one in four of these mothers had mental health issues and almost one in three had a history of abuse, which in turn may have placed their children at risk for developmental problems.
Notably, the PEDS is not diagnostic, but is rather a screening tool based on parent report of concerns. It assigns a level of risk of developmental problems based on those concerns. Thus, children who are identified as being at high risk for developmental problems may not actually be encountering developmental problems. Similarly, children whose parents do not express concerns about development may be delayed or at risk of behavioural/emotional problems. This possibility for misclassification by the PEDS must be considered when interpreting the regression model in this paper, yet the magnitude of the odds ratios and significance and consistency of the findings related to the impact of maternal factors suggest a notable relationship to child development $[14,18-20,25,28,52-54]$.

\section{Conclusions}

This study and the previous follow-up study indicate that the well-being of mothers is associated with developmental risk in children through the preschool years and at school entry. There is a consistent influence of maternal well-being on infant and child development, and an opportunity to better understand how women's well-being during pregnancy and early childhood can be optimized. Identifying women with a history of abuse and determining what strategies are needed to support their well-being and parenting has the potential to improve the life course trajectory for children and families. Thus, ongoing research and evaluation of interventions that enhance parenting and early assessment of child development is warranted. Failure to intervene when risk can be identified may limit efforts to optimize child development by school entry.

Additional file 1: Questionnaire used at 5 year follow-up with participants from the Community Perinatal Care Study cohort

\section{Acknowledgements}

This study was funded by the Calgary Children's Initiative of United Way of Calgary and Area. The Alberta Heritage Foundation for Medical Research provided salary support for SCT. The funding organization did not have a role in the study or in the preparation and submission of this manuscript. We thank the families who so graciously provided their time to complete these questionnaires and the Calgary Children's Initiative for their ongoing commitment to improved understanding of the well being of all children. We thank and appreciate the leadership in the Child and Women's Health, and Specialized Clinical Services portfolio of the Calgary Health Region for their ongoing support and enthusiasm for evidenced based program planning and practice. The study team acknowledges the content expertise and contributions of Sherry Hiebert-Keck of the Calgary Children's Initiative and Dr. Dawne Clark, Director of Child and Youth Studies, Mount Royal College. We appreciate the contribution of Dr. Francis Glascoe and colleagues for their interest and enthusiasm in regards to the Parents Evaluation of Developmental Status (PEDS). As well, we thank Sarah Horn and Carol Weller for their contribution to data collection, data entry and report design, and Heather Laursen and Monica Jack for their editorial assistance in preparing this manuscript. 


\section{Author details}

${ }^{1}$ Department of Paediatrics, Faculty of Medicine, University of Calgary, Calgary, Alberta, Canada. ${ }^{2}$ Department of Community Health Sciences, Faculty of Medicine, University of Calgary, Calgary, Alberta, Canada. ${ }^{3}$ Public Health Innovation and Decision Support, Population and Public Health, Alberta Health Services, Calgary, Alberta, Canada. ${ }^{4}$ Faculty of Nursing, University of Calgary, Calgary, Alberta, Canada. ${ }^{5}$ Decision Support Research Team, Alberta Health Services, Calgary, Alberta, Canada. ${ }^{6}$ Behavioural Research Unit, Alberta Children's Hospital, Calgary, Alberta, Canada.

\section{Authors' contributions}

SCT conceived and designed the study, contributed to the interpretation of data, and drafted the manuscript. JES carried out the analysis of the data, contributed to the interpretation of data, and revised the manuscript for important intellectual content. KB and SL contributed substantially to the interpretation of data and revised the manuscript for important intellectual content. DWJ coordinated the research study and revised the manuscript for important intellectual content. All authors read and approved the final manuscript.

\section{Competing interests}

The authors declare that they have no competing interests.

Received: 2 April 2009 Accepted: 25 March 2010

Published: 25 March 2010

\section{References}

1. Guralnick MJ: Effectiveness of early intervention for vulnerable children: a developmental perspective. Am J Ment Retard 1998, 102:319-345.

2. Hertzman C, Wiens M: Child development and long-term outcomes: a population health perspective and summary of successful interventions. Soc Sci Med 1996, 43:1083-1095.

3. Campbell FA, Ramey CT, Pungello E, Sparling J, Miller-Johnson S: Early childhood education: young adult outcomes from the Abecedarian Project. Applied Developmental Science 2002, 6:42-57.

4. Guralnick MJ: Early intervention for children with intellectual disabilities: current knowledge and future prospects. Journal of Applied Research in Intellectual Disabilities 2005, 18:313-324.

5. Hertzman C, Power C: Child development as a determinant of health across the life course. Current Paediatrics 2004, 14:438-443.

6. Mustard JF: Early Child Development and Experience-based Brain Development: The Scientific Underpinnings of the Importance of Early Child Development in a Globalized World Washington, DC: The Brookings Institution 2006

7. Reynolds AJ, Temple JA, Ou SR: School-based early intervention and child well-being in the Chicago Longitudinal Study. Child Welfare 2003, 82:633-656.

8. Heckman JJ, Masterov DV: The productivity argument for investing in young children. Review of Agricultural Economics 2007, 29:446-493.

9. Willms JD: Vulnerable Children: Findings from Canada's National Longitudinal Survey of Children and Youth Edmonton: University of Alberta Press 2002.

10. Brownell M, Roos N, Fansoo R, Guevremont A, McWilliam L, Derksen S, Dik N, Bogdanovic B, Sirski M: How Do Educational Outcomes Vary With Socioeconomic Status? Key Findings From The Manitoba Child Health Atlas 2004 Winnipeg: Manitoba Centre for Health Policy 2004.

11. Center on the Developing Child at Harvard University: A Science-Based Framework for Early Childhood Policy: Using Evidence to Improve Outcomes in Learning, Behaviour, and Health for Vulnerable Children 2007 [http://www. developingchild.harvard.edu].

12. Duncan GJ, Brooks-Gunn J, Klebanov PK: Economic deprivation and early childhood development. Child Dev 1994, 65:296-318.

13. Sameroff AJ, Seifer R, Barocas R, Zax M, Greenspan S: Intelligence quotient scores of 4-year-old children: social-environmental risk factors. Pediatrics 1987, 79:343-350.

14. Tough SC, Siever J, Leew S, Johnston DW, Benzies K, Clark D: Maternal mental health predicts risk of developmental problems at 3 years of age: follow up of a community based trial. BMC Pregnancy and Childbirth 2008, 8:16.

15. Kohen DE, Brooks-Gunn J, Leventhal T, Hertzman C: Neighborhood income and physical and social disorder in Canada: associations with young children's competencies. Child Dev 2002, 73:1844-1860.
16. Kenner C, D'Apolito K: Outcomes for children exposed to drugs in utero. J Obstet Gynecol Neonatal Nurs 1997, 26:595-603.

17. Streissguth AP, Barr HM, Sampson PD: Moderate prenatal alcohol exposure: effects on child IQ and learning problems at age $71 / 2$ years. Alcohol Clin Exp Res 1990, 14:662-669.

18. Belsky J: The determinants of parenting: a process model. Child Dev 1984, 55:83-96.

19. Dawson $G$, Ashman $S B$, Carver $L J$ : The role of early experience in shaping behavioral and brain development and its implications for social policy. Dev Psychopathol 2000, 12:695-712.

20. Hertzman C: The case for an early childhood development strategy. Canadian Journal of Policy Research 2000, 1:11-18.

21. Gutteling BM, de Weerth C, Willemsen-Swinkels SHN, Huizink AC, Mulder EJH, Visser GHA, Buitelaar JK: The effects of prenatal stress on temperament and problem behavior of 27-month-old toddlers. Eur Child Adolesc Psychiatry 2005, 14:41-51.

22. Koverola C, Papas MA, Pitts S, Murtaugh C, Black MM, Dubowitz H: Longitudinal investigation of the relationship among maternal victimization, depressive symptoms, social support, and children's behavior and development. J Interpers Violence 2005, 20:1523-1546.

23. Burke JG, Lee $L, O^{\prime} C a m p o ~ P:$ An exploration of maternal intimate partner violence experiences and infant general health and temperament. Matern Child Health J 2008, 12:172-179.

24. Murray L, Cooper PJ: Postpartum depression and child development. Psychol Med 1997, 27:253-260.

25. Weinberg MK, Tronick EZ: The impact of maternal psychiatric illness on infant development. J Clin Psychiatry 1998, 59:53-61.

26. Grace SL, Evindar A, Stewart DE: The effect of postpartum depression on child cognitive development and behavior: a review and critical analysis of the literature. Arch Women Ment Health 2003, 6:263-274.

27. Civic D, Holt VL: Maternal depressive symptoms and child behavior problems in a nationally representative normal birthweight sample. Matern Child Health J 2000, 4:215-221.

28. Abrams SM, Field T, Scafidi F, Prodromidis M: Newborns of depressed mothers. Infant Mental Health Journal 1995, 16:233-239.

29. Dickstein S, Seifer R, Albus KE: Maternal adult attachment representations across relationship domains and infant outcomes: The importance of family and couple functioning. Attachment \& Human Development 2009, 11:5-27.

30. Lee LC, Halpern CT, Hertz-Picciotto I, Martin SL, Suchindran CM: Child care and social support modify the association between maternal depressive symptoms and early childhood behaviour problems: A US national study. J Epidemiol Community Health 2006, 60:305-310.

31. Melson GF, Ladd GW, Hsu HC: Maternal support networks, maternal cognitions, and young children's social and cognitive development. Child Dev 1993, 64:1401-1417.

32. Tough SC, Johnston DW, Siever J, Jorgenson G, Slocombe L, Lane C, Clarke M: Does supplementary prenatal nursing and home visitation support improve resource utilization in a system of universal health care? Results from a randomized controlled trial in Canada. Birth 2006, 33:183-194.

33. Statistics Canada: Household Income Groups (24) in Constant (2005) Dollars, Household Type (3) and Presence and Combination of Children (11) for the Family Households of Canada, Provinces, Territories, Census Metropolitan Areas and Census Agglomerations, 2000 and 2005 - 20\% Sample Data (2006 Census of Population, Statistics Canada catalogue no.97-563-XCB2006048) 2009 [http://www.statcan.gc.ca].

34. Glascoe FP: Collaborating With Parents: Using Parents' Evaluation of Developmental Status (PEDS) to Detect and Address Developmental and Behavioral Problems Nashville, TN: Ellsworth \& Vandermeer 2002.

35. Glascoe FP: Parents' concerns about children's development: prescreening technique or screening test? Pediatrics 1997, 99:522-528.

36. Glascoe FP: PEDS Score Form Nashville, TN: Ellsworth \& Vandermeer Press 1997.

37. Corrigan A: Social Competence Scale - Parent Version, Grade 1/Near2 (Fast Track Project Technical Report) 2002 [http://www.fasttrackproject.org/ techrept $/ \mathrm{s} / \mathrm{scp} / \mathrm{scp} 2$ tech.pdf].

38. Ware JE, Kosinski M, Deway JE, Gandek B: How To Score and Interpret Single Item Health Status Measures: A Manual For Users of the SF-8 Health Survey Lincoln, Rl: QualityMetric Incorporated 2001. 
39. Sherbourne C, Stewart AL: MOS Social Support Survey. Soc Sci Med 1991, 32:705-714.

40. Johnston C, Mash EJ: A measure of parenting satisfaction and efficacy. $J$ Clin Child Psychol 1989, 18:167-175.

41. Trute B, Hiebert-Murphy D: Predicting family adjustment and parenting stress in childhood disability services using brief assessment tools. J Intellect Dev Disabil 2005, 30:217-255.

42. Cardiff: TeleForm.[Release 10.1] Vista, CA: Cardiff 2006.

43. StataCorp: Stata. Release 10.0] College Station, TX: Stata Corporation 2008.

44. Wathen CN, MacMillan HL, Canadian Task Force on Preventive Health Care: Prevention of violence against women: recommendation statement from the Canadian Task Force on Preventive Health Care. CMAJ 2003, 169:582-584.

45. MacMillan HL, Wathen CN, Jamieson E, Boyle M, MCNutt LA, Worster A, Lent B, Webb M, McMaster Violence Against Women Research Group: Approaches to screening for intimate partner violence in health care settings: a randomized trial. JAMA 2006, 296:530-536.

46. Muller RT, Gragtmans K, Baker R: Childhood physical abuse, attachment, and adult social support: test of a mediational model. Canadian Journal of Behavioural Science 2008, 40:80-89.

47. Michalski JH: Making sociological sense out of trends in intimate partner violence: the social structure of violence against women. Violence Against Women 2004, 10:652-675.

48. Rydz D, Shevell Ml, Majnemer A, Oskoui M: Developmental screening. J Child Neurol 2005, 20:4-21.

49. Williams J, Holmes CA: Improving the early detection of children with subtle developmental problems. J Child Health Care 2004, 8:34-46.

50. King TM, Glascoe FP: Developmental surveillance of infants and young children in pediatric primary care. Curr Opin Pediatr 2003, 15:624-629.

51. Chalmers B, Dzakpasu S, Heaman M, Kaczorowski J: The Canadian maternity experiences survey: an overview of findings. J Obstet Gynaecol Can 2008, 30:217-228.

52. Health Canada: Canadian Perinatal Health Report, 2003 Ottawa, ON: Minister of Public Works and Government Services Canada 2003.

53. Murray L, Woolgar M, Murray J, Cooper P: Self-exclusion from health care in women at high risk for postpartum depression. J Public Health Med 2003, 25:131-137.

54. Pevalin DJ, Wade TJ, Brannigan A, Sauve R: Beyond biology: the social context of prenatal behaviour and birth outcomes. Soz Praventivmed 2001, 46:233-239.

55. Young AF, Powers JR, Bell SL: Attrition in longitudinal studies: who do you lose? Aust N Z J Public Health 2006, 30:353-361.

56. Tough SC, Siever J, Johnston DW: Retaining women in a prenatal care randomized controlled trial in Canada: implications for program planning. BMC Public Health 2007, 7:148.

\section{Pre-publication history}

The pre-publication history for this paper can be accessed here:http://www. biomedcentral.com/1471-2431/10/19/prepub

doi:10.1186/1471-2431-10-19

Cite this article as: Tough et al:: Maternal well-being and its association to risk of developmental problems in children at school entry. $B M C$

Pediatrics 2010 10:19.

\section{Submit your next manuscript to BioMed Central and take full advantage of:}

- Convenient online submission

- Thorough peer review

- No space constraints or color figure charges

- Immediate publication on acceptance

- Inclusion in PubMed, CAS, Scopus and Google Scholar

- Research which is freely available for redistribution

Submit your manuscript at www.biomedcentral.com/submit
Ciomed Central 